\title{
PELATIHAN PEMBELAJARAN BAHASA ARAB BERBASIS E-LEARNING DI MADRASAH IBTIDAIYAH MIFTAHUL KHAIR BANJARMASIN
}

\author{
Try Viananda Nova M, Rina Alfah, dan Ibrahim \\ Fakultas Teknologi Informasi, Universitas Islam Kalimantan MAB \\ Email :novamegariani@gmail.com
}

\begin{abstract}
Our Action are to Introduce and provide other skills and benefits of E-Learning Arabic language subjects to students from Madrasah Ibtidaiyah Miftahul Khair Banjarmasin and teachers also to let them know that E- Learning is one of the solutions to provide creative and innovative lessons and to increase children's interest in Arabic subjects. This activity aims to introduce and give lessons to students / students and teachers of Madrasah ibtidaiyah miftahul khair using E-Learning media subjects Arabic language for students to be eager in receiving lessons Especially subjects of Arabic and teachers are more skilled and can apply the modern way of teaching using the media.
\end{abstract}

Keywords : E-learning

\section{PENDAHULUAN}

Madrasah Ibtidaiyah adalah sekolah yang setara dengan sekolah dasar (SD) sebagai perbedaan nya, Madrasah Ibtidaiyah (MI) memiliki mata pelajaran agama yang lebih banyak misalnya ada Al Qur'an dan hadist, Aqidah Akhlak, Tauhid, Bahasa Arab dll. Sebuah Madrasah Ibtidaiyah harusnya bisa bersaing secara kompeten dengan

Sekolah dasar dalam memberikan mata pelajaran secara menarik agar anak didik menjadi bersemangat dalam menerima pelajaran Khususnya mata pelajaran Bahasa Arab karena banyak sekali hapalan yang harus mereka setorkan kepada gurunya. Salah satu sekolah / madrasah tersebut yaitu
Madrasah Ibtidaiyah Miftahul khair yaitu sekolah yang berada di desa Basirih Kubah , tepatnya di Kecamatan Banjarmasin Barat Kota Banjarmasin, Kalimantan selatan . Sekolah ini memiliki murid dan guru yang sangat sedikit untuk sebuah sekolah di daerah pinggiran Kota Banjarmasin. Seharusnya keadaan ini bisa diatasi dengan memberikan suatu metode pengajaran yang lebih menarik setiap harinya. Misalnya saja dengan memberikan E-Learning , terutama dalam pelajaran Bahasa Arab. Agar Minat Masyarakat untuk memasukkan anaknya ke sekolah ini bisa lebih meningkat karena sebagai orang tua tentunya ingin anaknya nya mempunyai 
bekal ilmu agama Islam sejak dini agar kelak mereka bisa menjadi muslim yang taat kepada Allah serta bisa dengan lebih mudah melanjutkan sekolah ke tingkatan selanjutnya seperti madrasah Tsanawiah yaitu sekolah yang setara dengan SLTP tapi tentunya dengan tambahan mata pelajaran agama yang lebih banyak dari pada sekolah umum (SLTP).

\section{KHALAYAK SASARAN}

Pengabdian kepada masyarakat ini dilaksanakan melalui Pelatihan dan pengajaran berbasis E-Learning di Madrasah Ibtidaiyah Miftahul Khair yang beralamat : Jl. Basirih Kubah Banjarmasin, Kegiatan ini berlangsung selama 3 jam pada Tanggal. 07/09/2017 s/d 09/09/2017. Jumlah peserta yang ikut berpartisipasi yaitu : 20 (dua Puluh ) orang yaitu para guru (ustadz dan Ustadzah) dan pewakilan murid

\section{METODE PELAKSANAAN KEGIATAN}

Kegiatan Pengabdian Masyarakat ini menggunakan metode praktek dengan Presentasi,dan Tanya Jawab secara langsung. Instruktur akan menjelaskan bagaimana para peserta bagaimanakan bentuk E-Learning mata pelajaran Bahasa Arab itu, Setiap peserta bisa melihat dan mendengarkan setiap sesi pembelajaran melalui LCD dari Laptop Instruktur. kemudian setiap peserta dapat langsung bertanya kepada Tim Pengabdian pada masyarakat yang mendampingi mereka selama kegiatan berlangsung.

\section{IMPLEMENTASI DAN}

\section{PEMBAHASAN}

Metode pembelajaran yang di sosialisasikan adalah Aplikasi Arabindo http://arabindo.co.nr. Terdapat menu utama di Beranda aplikasi tersebut yaitu : DEPAN , QAWAID , HIWAR , QIRA'AH , \& QAMUS.

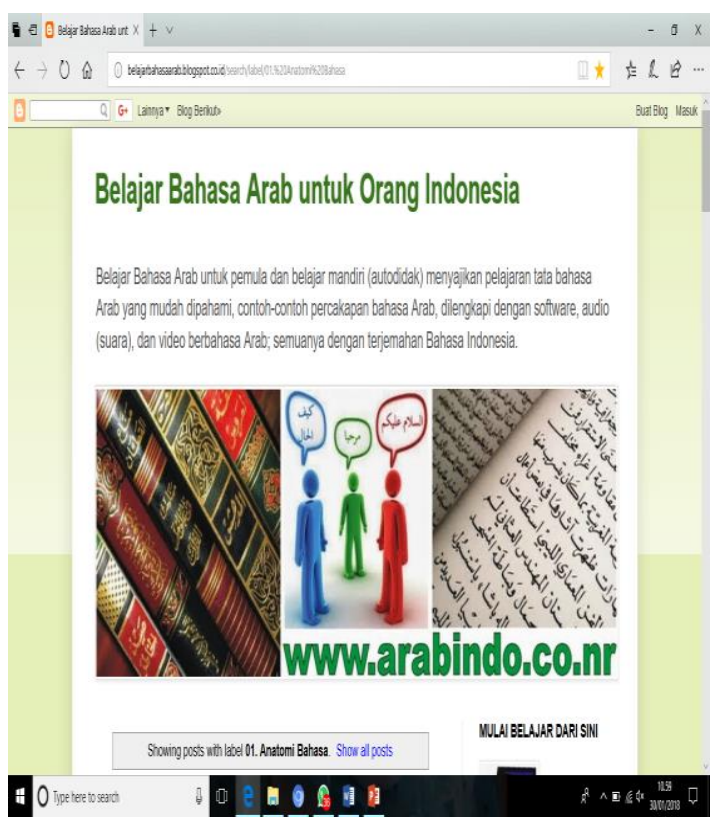


Pada menu Qawaid terdapat berbagai macam pilihan yang dapat kita buka , misalnya Anonim Bahasa yang dipergunakan dalam bahasa arab

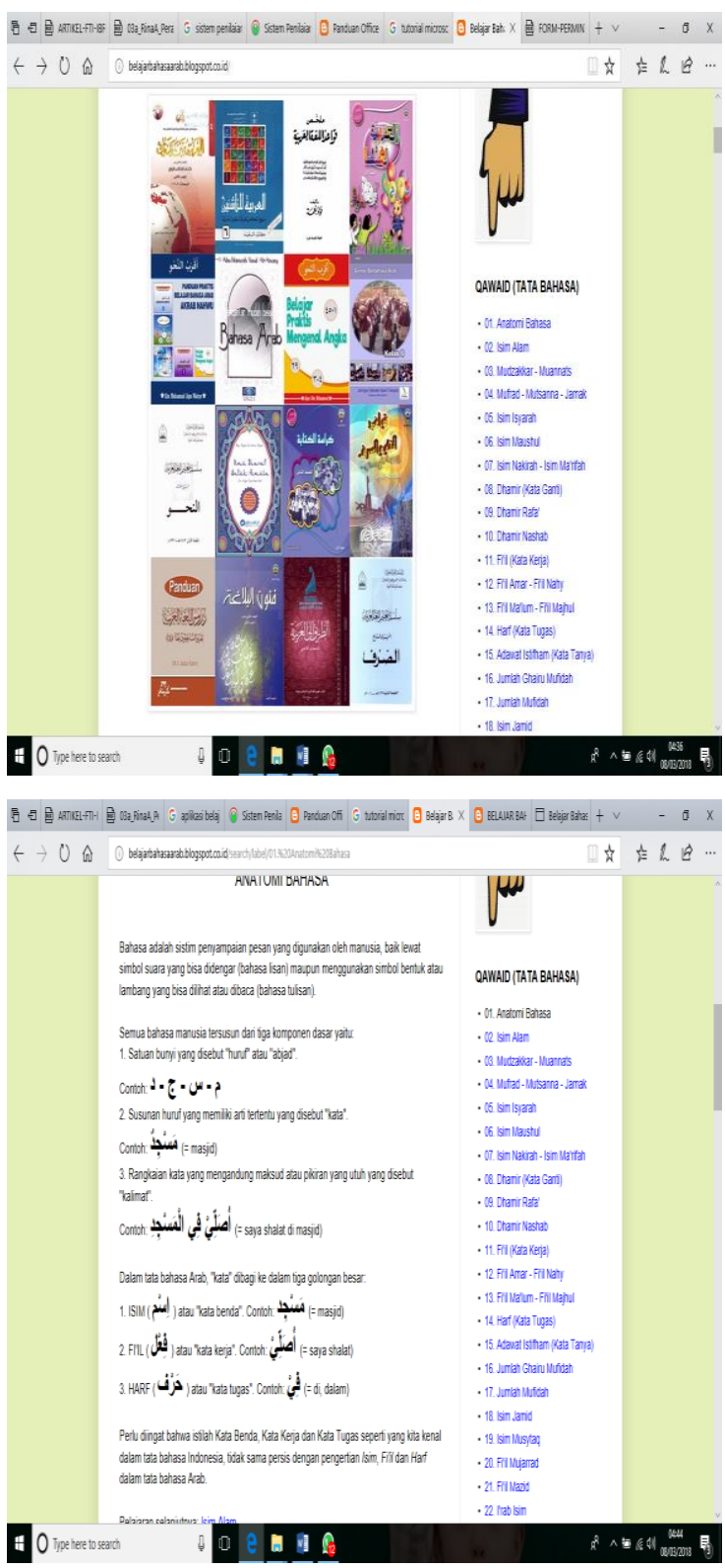

Pada menu Qawaid ada sekitar 30 (tiga Puluh) macam tata bahsa dalam bahsa arab yang dapat kita pilih. Selanjutnya pada Menu Hiwar (Percakapan) juga terdapat sekitar 30 (tiga puluh) pilihan .

misalnya Perkenalan , Kebangsaan dan profesi.
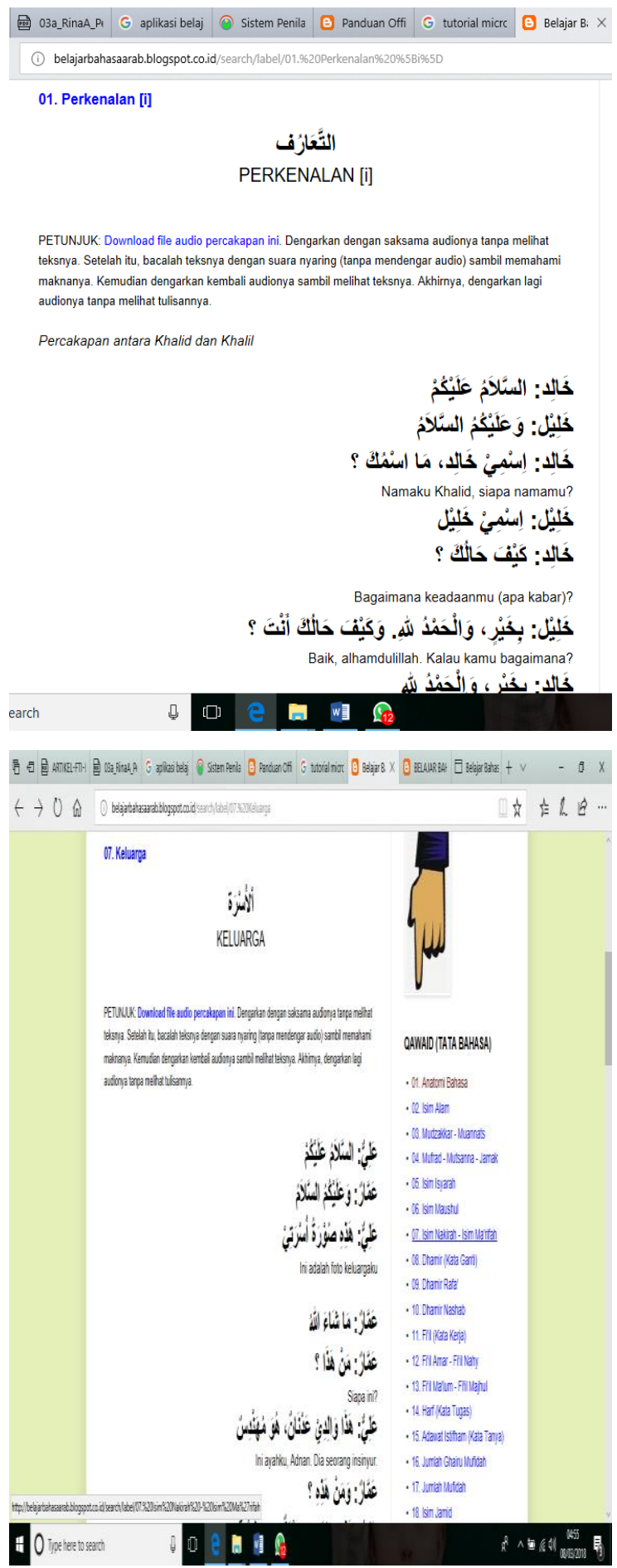
Volume 3 Nomor 2, April 2018

\section{FOTO KEGIATAN}
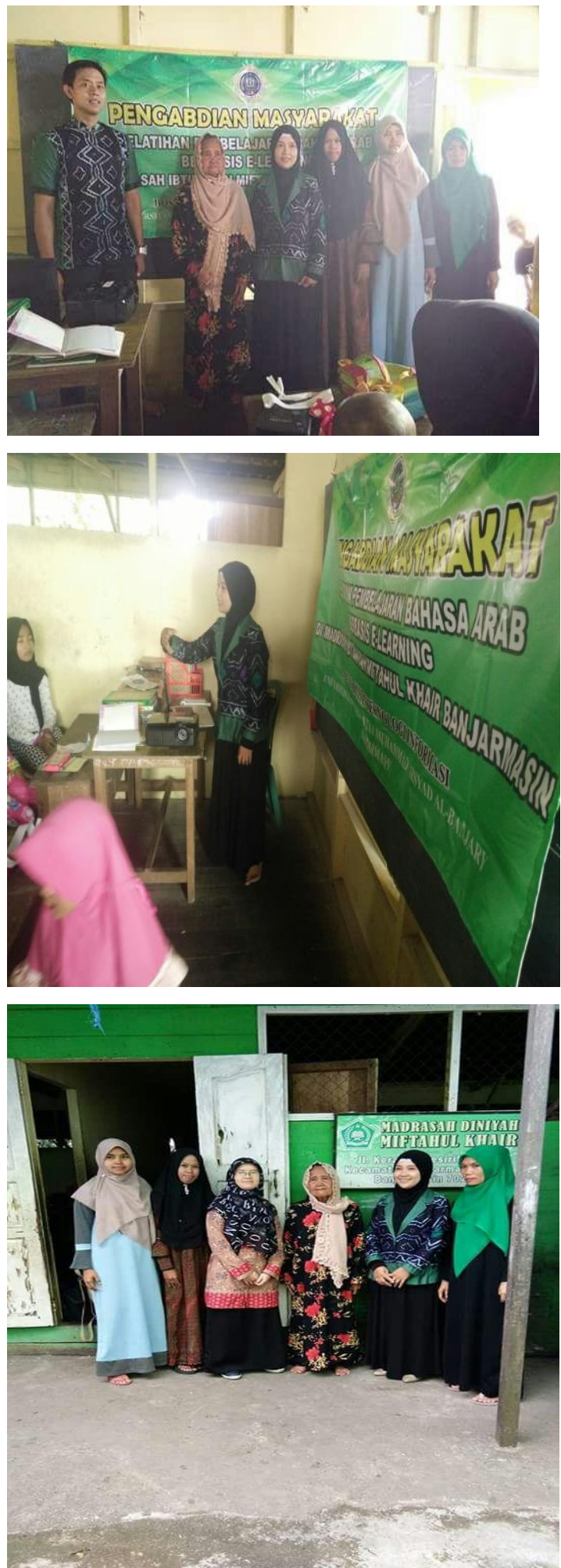
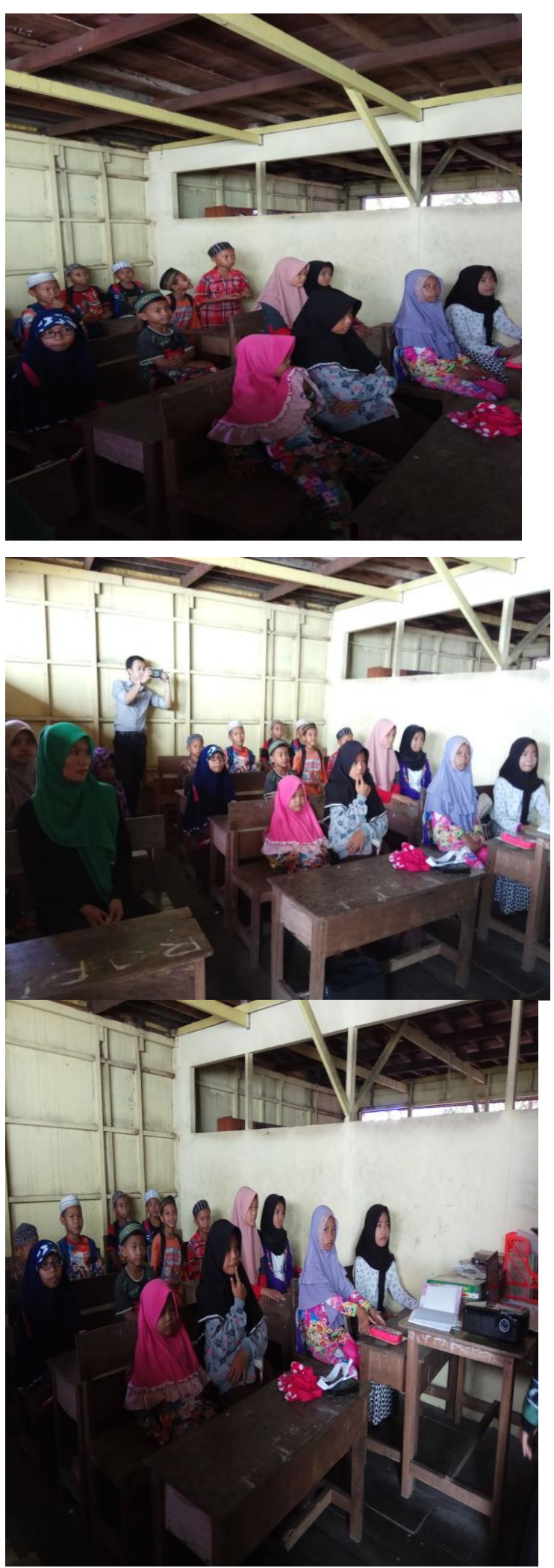


\section{KESIMPULAN}

Dengan diadakan kegiatan pengabdian masyarakat oleh dosen uniska di Madrasah Ibtidaiyah Miftahul Khair ini Terlihat sekali Antusiasme Para Guru Dan Anak didik dalam menyimak Materi. Mereka menjadi tahu bahwa ELearning adalah salah satu solusi memberikan pelajaran secara kreatif dan inovatif serta meningkatkan minat anak terhadap mata pelajaran bahasa arab. Karena kegiatan ini memang bertujuan untuk Memperkenalkan Dan Memberikan pembelajaran kepada para Murid/ anak murid dan para guru madrasah ibtidaiyah miftahul khair dengan menggunakan media ELearning mata pelajaran Bahasa Arab agar anak didik menjadi bersemangat dalam menerima pelajaran Khususnya mata pelajaran Bahasa Arab.

Saran

Pada Madrasah Ibtidaiyah ini seharusnya memiliki Fasilitas Proyektor untuk melakukan tambahan kegiatan belajar mangajarnya terutama Eleaning.

Dikarenakan Terbatasnya Biaya, maka Kedepannya untuk Pengabdian Kepada Masyarakat Selanjutnya, kami akan memberikan Kenangan berupa Proyektor LCD untuk menunjang Kegiatan Belajar / ELearning Kepada anak-anak Madrasah Miftahur Khair ini

\section{DAFTAR PUSTAKA}

Ulfa, Maria. (2012). Interactive Elearning untuk Belajar Mandiri Anak. Jurnal Sarjana Institut Teknologi Bandung Bidang Teknik Elektro dan Informatika.

Kusni, M. (2010).”Implementasi Sistem Pembelajaran Blended Learning pada Matakuliah AE3121 Getaran Mekanik" di Program Aeronotika dan Astonotika, Seminar Tahunan Teknik Mesin.

Priyatni, Endah Tri., dan Wahono, Asnawi Susilo. (2010). "Pengembangan Perangkat Pembelajaran Membaca SD Berbasis Pendidikan Multikultural dan E-Learning". Jurnal Penelitian Kependidikan. 20. (2). 156-166.

http://belajarbahasaarab.blogspot.co.id/ Diakses tgl 17 Juli 2017 